msh-mss Mathématiques et sciences humaines

133 | Printemps 1996

Tournois et analyse des préférences ordinales

\title{
Solutions de tournois : un spicilège
}

Tournaments solutions: a survey

Jean-François Laslier

\section{OpenEdition}

Journals

Édition électronique

URL : http://journals.openedition.org/msh/2739

DOI : $10.4000 /$ msh. 2739

ISSN : 1950-6821

\section{Éditeur}

Centre d'analyse et de mathématique sociales de l'EHESS

Édition imprimée

Date de publication : 1 mars 1996

ISSN : 0987-6936

\section{Référence électronique}

Jean-François Laslier, « Solutions de tournois : un spicilège », Mathématiques et sciences humaines [En ligne], 133 | Printemps 1996, mis en ligne le 10 février 2006, consulté le 23 juillet 2020. URL : http:// journals.openedition.org/msh/2739; DOI : https://doi.org/10.4000/msh.2739

Ce document a été généré automatiquement le 23 juillet 2020

(C) École des hautes études en sciences sociales 


\section{Solutions de tournois : un spicilège}

Tournaments solutions: a survey

Jean-François Laslier

RÉSUMÉS

L'article passe en revue quelques solutions de tournois (correspondances de choix définies sur les tournois). On compare ces solutions entre elles, et on mentionne certaines de leurs propriétés.

The article is a survey of some existing Tournament Solutions (Choice correspondences defined on tournaments). We compare these solutions and mention some of their properties.

INDEX

Thèmes : graphes, jeux (théorie des), ordres et préordres, préférences (agrégation des) 